\title{
EPIDEMIOLOGY OF SNAKEBITE; A STUDY FROM CHOHARWA ARMY CAMP, SIRAHA, NEPAL
}

\author{
Devkota U N ${ }^{1}$, Steinmann $\mathbf{J ~ P}^{2}$, Kathayat $\mathbf{J ~ B}^{1}$
}

\section{ABSTRACT}

Snakebite is an occupational health hazard seen mostly among farmers, hunters and herders. In Nepal, 23 districts from terai and inner terai region have been reporting snakebite case every year. Limited studies have been conducted so far, to understand the epidemiology of snakebite in Nepal. This study is an attempt to highlight some of the aspects of snakebite epidemiology in Nepal.

Siraha is one of the districts where an increase in snakebite cases has been observed every year. Apart from government health institutions, the army camp at Choharwa has been found providing snakebite treatment for civilian population very effectively. This is a retrospective study of 279 cases of suspected snakebite that presented at the camp for treatment in the year 2000.

Incidence of snakebite was slightly higher among males (53\%) than females $(47 \%)$ and more frequent in 15-45 years $(67 \%)$ age group. The highest incidence occurred during the monsoon from June to October (76\%), with peak in August. Majorities of the victims were farmers $(\mathbf{7 3 \%})$ and bitten mostly by kraits $(27 \%)$ on the lower extremity (58\%), especially on the leg (48\%). Snakebite victims were mostly bitten in daytime $(61 \%)$. Outdoor activities had more risk $(57 \%)$ for snakebite. The high-risk activities identified were grass cutting $(25 \%)$ and sleeping $(23 \%)$ on the ground. Tourniquets were the main first aid measure used by the victims $(86 \%)$. Mostly, victims were brought to the camp with in one hour after the bite $(61 \%)$. The average duration of stay in the camp was 18-24 hours in a non-poisonous bite and 2-3 days in poisonous.

1. Epidemiologist and Disease Control Expert, Primary Health Care Project - GTZ

2. Programme Manager, Health Sector Support Programme - GTZ

3. Comapny Commander, Shree Bhawani Dal Gulm, Choharwa, Siraha

Address for correspondence : $\quad$ Dr. U. N. Devkota, Primary Health Care Project - GTZ

Department of Health Services, Teku, Kathmandu, Nepal.

P. O. Box: 1457

Ph. No.: 0977-1-01261404, Fax: 099-1-261079

Email: phcp@gtz.org.np 


\section{INTRODUCTION}

Globally more than 3,500 species of snakes have been identified of which about 500 are poisonous. In Nepal, a total of 75 species of snakes have been reported so far, in which 20 are poisonous. The most commonly found poisonous snakes from terai and inner terai includes, 4 species of krait, 3 species of cobra, 9 species of viper, 1 species each of coral snake, Himalayan pit viper, mountain pit viper and Russel's viper. The distribution of these poisonous snakes depends largely on the geography and climate. The Himalayan pit viper has been found up to an altitude of 5,000 meters whereas the pit vipers inhibit wooded mountain slopes below 3,000 meters. The species of krait are found below 2,000 meters while the species of cobras are confined to the terai. ${ }^{1,3}$

Snakebite is an occupational health hazard seen most among farmers, hunters, and herders in tropical and sub-tropical countries. In Nepal, 23 districts from terai and inner terai region have been reporting snakebite cases every year. In Nepal, the exact morbidity and mortality from snakebite is very difficult to estimate due to lack of reliable data. Records of snakebite victims treated by traditional methods are lost to the official statistics and hospital records is the only source of information of most snakebite reported in Nepal. It has been estimated that more than 20,000 cases of snakebite with 1000 deaths occur every year in Nepal. ${ }^{1}$ In a study a total of 3,225 snakebite cases with 144 deaths for the period 1980-85 have been reported (case fatality $4.5 \%) .^{2}$ In Nepal, the available data on snakebite has shown a definite seasonal pattern with the highest incidence during the monsoon from June to October, with a peak in August. Due to chronic shortage of anti snake venom (ASV) in government hospitals and strong belief in traditional remedies most victims of snakebite prefer to go to "Dhami"or "Jhankri". Only when the symptoms deteriorate then the victims are brought to hospital but many are thought to die on the way.
The Bhawani Dal Gulm (A Royal Nepal Army Company) is situated on the East-West Highway in Chandra-Ayodhayapur village development committee at Choharwa in Siraha district. Usually the medical facilities in the Royal Nepal Army are restricted to the army personnel and their families only. But considering the severity of the snakebite problem in the district, the Choharwa Army Camp (CAC) have been providing snakebite treatment facility for civilians since 1997.

\section{MATERIALS AND METHODS}

A total of 279 case files of snakebite victims with a history of suspected snakebite during the period January to December 2000 were reviewed. Necessary data and information on snakebite victims were extracted from the snakebite register available at Choharwa Army Camp (CAC) treatment center. All the data were analyzed for the epidemiological features of snakebite with details of age, sex, occupation, biting sites, location of bite, activities carried out during biting, seasonal variation etc.

\section{RESULTS}

The study has revealed that a total of 279 cases of snakebite were treated in Choharwa army camp during January to December 2000. Based on the estimated service catchment area population $(65,000$ population) of Choharwa army camp, the incidence rate of snakebite is $4.3 / 1,000$ population. It is found that the snakebite cases were almost equally distributed in both the sexes although, males have shown slightly higher proportion. There were 53\% $(\mathrm{N}=147)$ male and $47 \%(\mathrm{~N}=132)$ female. When age was considered it was found that all the age groups were the victims of snakebite and ranged from 2 to 80 years with mean age of 26 years. The age group between 15-45 years constituted the major group of snakebite victims (67\%) (Fig. 1). The next age group found common was $10-14$ years (23\%). These figures supplement the results published elsewhere. ${ }^{1}$ 
Fig. 1 Snakebite cases by age groups, CAC, Siraha, 2000

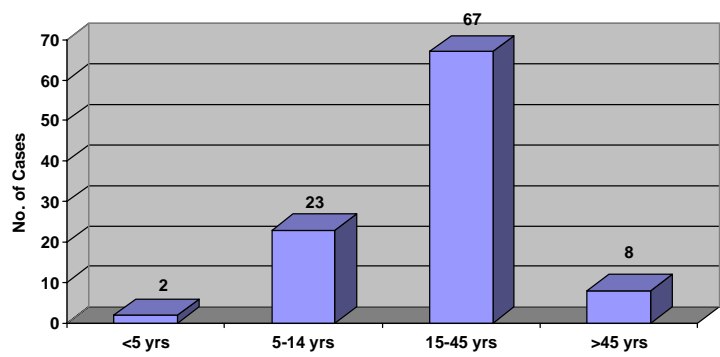

Results have also shown that occupation has an important role in snakebite. Among the total cases a large proportion $(73 \%)$ of the victims were farmers while rest $(27 \%)$ were students, shopkeepers, teachers and carpenters (Fig. 2). These figures

Fig. 2 Snakebite cases by occupation, CAC, Siraha, 2000

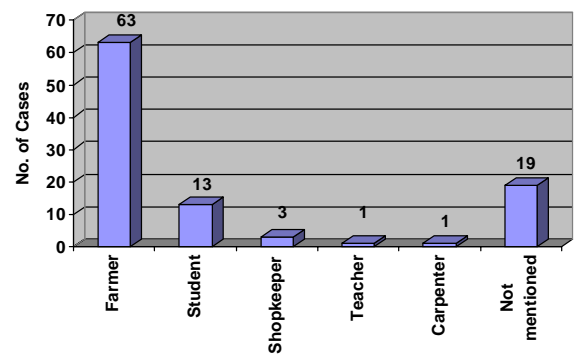

coincide with the results of previous study. ${ }^{3}$

Analysis of the activities performed by the victims at the time of bite revealed that among all activities, majorities of bites occurred while the victims were engaged in grass cutting (25\%) and sleeping (23\%) on ground (Fig.3). Results have also shown that

Fig. 3 Snakebite cases by activities, CAC, Siraha, 2000

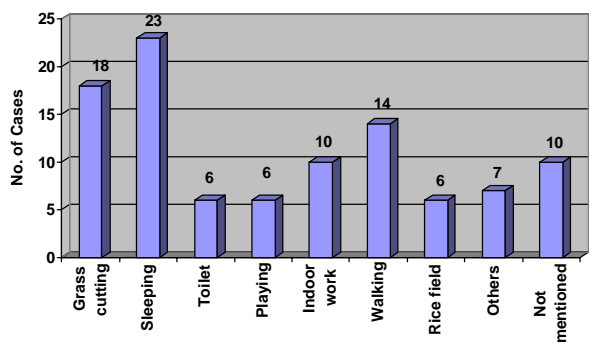

working inside the house $(10 \%)$ and walking mostly in darkness $(15 \%)$ were another important risk activities in snakebite.
In contrast to the general belief that snakes mostly bite at night, the study has shown that most of the cases of snakebite occurred during the daytime (61\%) (Fig.4). Although, the percentage of bite at

Fig. 4 Snakebite cases by time of day, CAC, Siraha, 2000

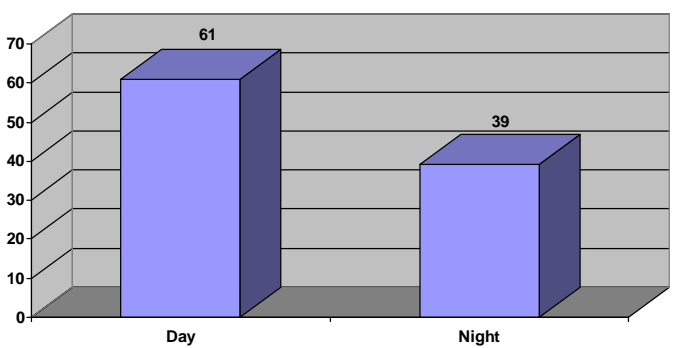

night was less (39\%) it was interesting to observe that most of the poisonous bite $(67 \%)$ occurred at night. When location of activity was considered it was found that outdoor activities have more risk for snakebite compared to indoor activities. It was observed that $57 \%$ of the victims were bitten in outdoor activities in contrast to $35 \%$ indoor activities (Fig. 5). Among the outdoor activities,

Fig. 5 Snakebites by location of activity, CAC, Siraha, 2000

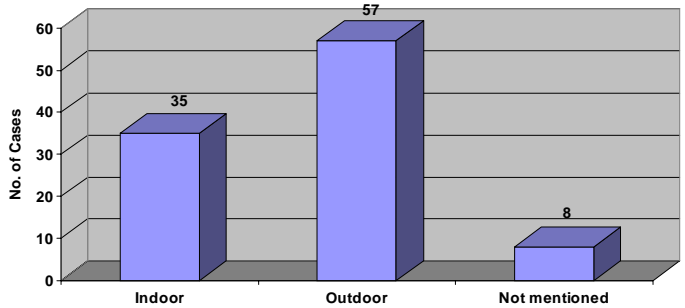

grass cutting (31\%) and walking in dark (26\%) constituted the major risk activities. Among indoor activities, $65 \%$ of the victims were bitten during sleeping.

It was found that most of the victims were bitten on the lower extremity (58\%), especially on the leg $(48 \%)$. In the upper extremity most of the cases were bitten on hand (28\%) (Fig.6). Very few cases were bitten on head and back.

Although, the snakebite cases were reported throughout the year, the study has clearly shown 


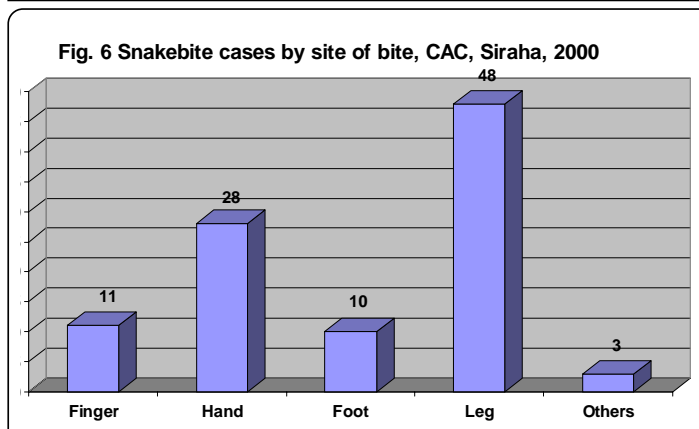

that snakebite is a seasonal event. The highest incidence of snakebite occurred during the monsoon from June to October (76\%), with a peak in August. Thereafter, the snakebite cases gradually reduced in number and maintained at a lower rate for rest of the year (Fig. 7). Similar results were also observed

Fig. 7 Snakebite cases by months, CAC, Siraha, 2000

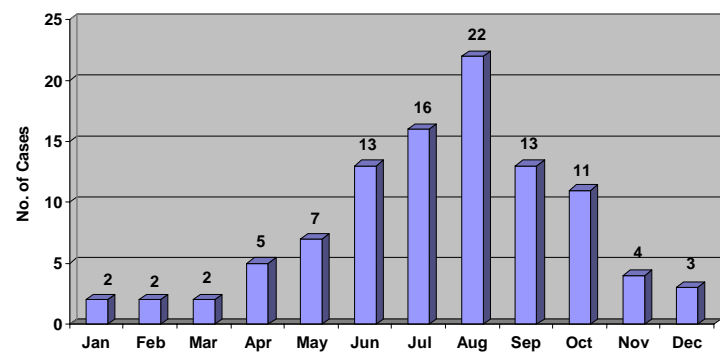

by David Warrell in one of the studies. ${ }^{2}$

Among the total snakebite victims, only 79 claimed to have seen and identified the snakes. It was found that $27 \%$ of the victims were bitten by krait whereas only $1 \%$ by cobra. Tourniquet was found to be the main first aid procedure used by the victims (86\%). Only a small proportion (2\%) used other measures such as incision and sucking of the wound. Twelve percentages of the victims did not use any first aid procedures.

The snakebite victims were brought to the camp as early as 20 minutes to as late as 5 hours after the bite. Majorities of the victims (61\%) were brought to the camp within one hour after the bite. Only $25 \%$ of the victims were brought within $1 / 2$ hours of the bite.
Although, there were 79 victims who identified the biting snake as krait and cobra, only 15 victims had shown features of envenomation and were treated with anti snake venom (ASV). Rests of the cases were managed conservatively with injection tetanus toxoid, injection dexamethasone and intravenous fluid. A total of 294 vials of ASV were used with minimum 1 to maximum 49 vials (average 19.6 vials/case).

The average duration of stay of snakebite victims in the camp for the treatment was 18-24 hours in a nonpoisonous bite. Whereas, in a poisonous bite where ASV was used the average duration of stay was 2-3 days. Surprisingly, no death occurred during the treatment and all the cases were cured and discharged.

\section{DISCUSSION}

The age and sex incidence of snakebite victims has clearly shown that certain groups of population in the community are more vulnerable for snakebite. It has clearly shown that not only the males, but the females are equally exposed to the risk factors. Unlikely in the past, now a days woman in the terai community are more and more exposed in out door activities thus making themselves more susceptible for snakebite. In the study, $60 \%$ of woman were bitten in outdoor activities, which included grass cutting, walking in darkness and during defecation in open field in darkness. Among indoor activity most of the women (25\%) were bitten while sleeping in the night. It is a common practice in terai to sleep on the ground, particularly woman due to poor economic condition.

Although, the study has revealed that all the age groups were the victims of snakebite, the adults between 15-45 years were the main victims of snakebite. It could be attributed to the fact that in most of the terai community adults of both the sexes are equally involved in out door activities, especially during monsoon. Similar results were 
also observed in other studies in Nepal and India. ${ }^{1,4}$ In terai, it is common to find children between 1015 years busy in outdoor activities like grass cutting, grassing cattle, collecting firewood and working in fields thus exposing them for snakebite.

The high incidence of snakebite among farmers, as shown in the study, once again highlights the fact that snakebite is an occupational hazard. Grass cutting has been identified as the most high-risk activity for snakebite. It could be due to the fact that in terai people usually collect grass as a fodder in the field, forest, bamboo bushes, along the pond, river and stream bank, under bridges etc. where snakes could easily hide. Walking in dark with out shoes and torchlight is another high-risk activity mostly encountered with snakebite in terai. Mostly, snakes come out of their shelter at night in search of food. Therefore, sleeping on ground in rural communities could be another high-risk activity. The high incidence of snakebite during the daytime corresponds well with the period of maximum outdoor activity, which has also been observed in earlier studies. ${ }^{5}$

The observation that the most frequent biting site was the lower extremity suggests that in most cases the snake had been accidentally stamped., ${ }^{6,7}$ Although, the cases of snakebite were reported all the year round, the incidence of snakebite showed a distinct seasonal pattern in conformity with earlier reports. ${ }^{1,8}$ The high incidence of snakebite was closely related to monsoon activity, which compelled the snakes to come out of their shelter and pits due to high humidity and temperature.

The study has shown that large proportions of snakebite victims $(72 \%)$ were unable to identify the snake. It could be either due to the ignorance about snakes or poor visibility, as most of the snakebite occurred while cutting grass, walking in darkness and sleeping in the night. But those who identified, majority were bitten by krait. The application of tourniquet by majority of the victims $(86 \%)$ clearly indicates that communities are well aware of the first aid measure in snakebite. But, the proper technique to use a tourniquet in an illiterate terai community is questionable.

Mortality and morbidity in snakebite depends largely on the prompt medical aid and use of ASV therapy. In our study majority $(61 \%)$ of the victims were brought to the camp with in one hour of the bite. It shows that communities are well aware about the importance of quick medical treatment in snakebite. Usually bites from poisonous snakes are extremely rare and about half of the bites from poisonous snakes do not give significant envenomation and only a few needs ASV treatment. ${ }^{9}$ Although, 79 victims identified the snakes as krait and cobra, only 15 developed features of envenomation and treated with ASV. In the army camp no death was reported and all the cases were cured and discharged. Cases not showing the features of envenomation were kept under observation for a period of 18-24 hours whereas the poisonous cases were kept for 3 days before discharge.

\section{CONCLUSION}

The study has revealed that the incidence of snakebite in the catchment area of Choharwa army camp is very high. This incidence could be reduced significantly by using certain simple measures in the community. The community should be made aware that snakes are very shy, non-aggressive and always try to avoid humans. They attack only when they are disturbed or threatened. Poisonous snakes should never be kept as pets or as performing animals. ${ }^{7}$ Emphasis should be given to use protective clothing, shoes/boots, long trousers while walking in dark or in thick vegetation / forest. It is always wise to carry a torch / flashlight and a stick at night. If at all possible one should try to avoid sleeping on the ground. ${ }^{1}$ People should always beware of piles of wood, logs, boulders, debris and 
should not reach into blind holes where snakes might hide. Always avoid having rubble, rubbish, termite mounds or domestic animals close to human dwellings, as all of these attract snakes. If possible, avoid types of house construction that will provide snakes with hiding places (eg. thatched roof, mud and straw walls with large cracks and cavities).

The community should know the basic first aid procedures in snakebites. Emphasis should be given that snakebite can not be treated by traditional methods and "Dhami' or "Jhankri" and every case of snakebite should be transported as quickly as possible to a nearest health facility providing ASV treatment.

Since, most of the snakebites are non-poisonous and $50 \%$ bites from poisonous snakes do not manifest features of envenomation, simple supportive measures and observations over 24 hours would serve in most cases. Considering the cost and availability, ASV should be used quite discretely.

To reduce the morbidity and mortality from snakebite, an adequate and timely supply of ASV should be made to the hospitals and PHCs where it is needed. Regular training and follow up on snakebite management should be provided to the health personnel including PHCs and health posts. Standard treatment protocol on snakebite management should be developed and disseminated.

\section{ACKNOWLEDGEMENT}

Our sincere thanks go to the Epidemiology and Disease Control Division for providing adequate and timely supply of ASV and involving health personnel of the Choharwa army camp in their regular training programme on snakebite.
We are also thankful to the health personnel of the Choharwa army camp who supported us in using the format provided them for information collection.

\section{REFERENCES}

1. Devkota UN, Steinmann JP, Shah LN. Snakebite in Nepal, A study from Siraha district. Joumals of the Nepal Medical Association. Vol. 39; 203-209, 2000 .

2. Warrell DA, O' Shea M. Snakes and snakebite in Nepal. Tropical Doctor. Vol. 28; 223-226, 1998.

3. Hansdak SG, Lallar KS et. al. A clinicoepidemiological study of snakebite in Nepal. Tropical Doctor. Vol. 28; 223-226, 1998.

4. Hati AK, Mandal M, De MK et. al. Epidemiology of snakebite in the district of Burdwan, hest Bengal. J Indian Med Assoc. Vol. 90; 145-47, 1992.

5. Swamy Y, Homa M. Snakebite in India. Animal Plant and Microbial Toxins. India.Toxico, 1976.

6. Currie BJ, Sutherland SK, Hudson BJ, Smith AM. An epidemiological study of snakebite envenomation in Papua New Guinea. Med J Aust. Vol. 154; 266-8, 1991.

7. Warrell DA. WHO/SEARO guidelines for the clinical management of snakebites in the Southeast Asian Region. Vol. 30. 1999.

8. Bewes P, Holmgren G. Snakebite in East and Southern Africa. Nytt om U-landshalsovard. Vol. $11 ; 4-8,1997$.

9. Heap BJ, Cowan GO. The epidemiology of snakebite presenting to British mi litary Hospital, Dharan, during1989. J R Army Med Corps. Vol. 137; 123-5, 1991.

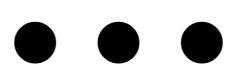

